\title{
Pentraxin-3 as a marker of disease severity and risk of death in patients with necrotizing soft tissue infections: a nationwide, prospective, observational study
}

Marco Bo Hansen ${ }^{1,2^{*}}$, Lars Simon Rasmussen ${ }^{1}$, Peter Garred ${ }^{3}$, Daniel Bidstrup ${ }^{2}$, Martin Bruun Madsen ${ }^{4}$ and Ole Hyldegaard ${ }^{1,2}$

\begin{abstract}
Background: New biomarkers are needed to assess the severity of necrotizing soft tissue infection (NSTI) at an early stage and to individualize treatment strategies. We assessed pentraxin-3 (PTX3) as a marker of disease severity and risk of death in patients with NSTI.

Methods: We conducted a prospective, observational study in the intensive care unit at Copenhagen University Hospital, where treatment of NSTI is centralized at a national level. We compared PTX3, procalcitonin and C-reactive protein in septic shock versus nonshock patients and in amputated versus nonamputated patients using the Mann-Whitney $U$ test. The prognostic value of the markers for 180-day mortality was assessed using Cox regression analyses.
\end{abstract}

Results: Patients with NSTI $(n=135)$ were included over 25 months with up to 2.5-year follow-up; $71 \%$ had septic shock, amputation was undertaken in $20 \%$ and the 180-day mortality was $27 \%$. Baseline plasma PTX3 level was significantly higher in patients with septic shock $(67.3$ versus $24.6 \mathrm{ng} / \mathrm{mL}, p<0.0001)$ and in patients who underwent amputation (118.6 versus $43.6 \mathrm{ng} / \mathrm{mL}, p=0.019$ ). No significant differences in baseline procalcitonin or C-reactive protein levels were found according to amputation ( 25.2 versus $7.0 \mu \mathrm{g} / \mathrm{L}, p=0.060$ and 202 versus $225 \mathrm{mg} / \mathrm{L}$, $p=0.123$ ), respectively. Baseline PTX3 level above the median was associated with death ( $p=0.009$, log-rank test) and the univariate Cox regression analysis revealed a significant association between PTX3 level upon admission and 180-day mortality (hazard ratio 2.60 (95 \% confidence interval 1.28-5.29), $p=0.008$ ). When adjusted for age, sex, chronic disease and Simplified Acute Physiology Score II, no significant association was found.

Conclusions: High PTX3 level is associated with septic shock, amputation and risk of death in patients with NSTI, but it is not an independent predictor of 180-day mortality in this patient group.

Trial registration: ClinicalTrials.gov Identifier: NCT02180906. Date of registration: June 29, 2014.

Keywords: Sepsis, Amputation, Survival, Procalcitonin, C-reactive protein, Necrotizing fasciitis

\footnotetext{
* Correspondence: marcobhansen@gmail.com

'Department of Anesthesia, Center of Head and Orthopedics, Rigshospitalet,

University of Copenhagen, Blegdamsvej 9, Copenhagen DK-2100, Denmark

${ }^{2}$ Hyperbaric Unit, Department of Anesthesia, Center of Head and

Orthopedics, Rigshospitalet, University of Copenhagen, Blegdamsvej 9,

Copenhagen DK-2100, Denmark

Full list of author information is available at the end of the article
} 


\section{Background}

Necrotizing soft tissue infection (NSTI) is a bacterial infection of any layer within the soft tissue compartments associated with necrosis. The condition is often accompanied by septic shock, and the extensive inflammatory response is thought to be a primary cause of mortality [1]. Delay of surgery has been shown to be an independent risk factor for mortality, and studies stress the importance of surgical debridement and early amputation of infected limbs [2-5]. However, an aggressive surgical approach increases the risk of severe disability and impaired quality of life. Moreover, surgical decisions are often based on the surgeon's experience and practice guidelines.

Biomarkers may provide therapeutic guidance and prognostication, and thereby improve decision-making in patients with NSTI. To date, C-reactive protein (CRP) and procalcitonin (PCT) have been used to monitor infectious disease progression in the intensive care unit (ICU). However, the literature investigating the value of biomarkers in patients with NSTI is sparse and often limited by retrospective study designs [6-8]. Due to the low incidence, the knowledge and evidence from septic patients are extrapolated to those with NSTI, even though the immunological reaction may differ because of the extensive tissue damage and different pathogenesis. It would be desirable if biomarkers could be used to identify patients with NSTI at high risk of death, as more aggressive treatment could then be undertaken in this subgroup while extensive surgery could be avoided in low-risk patients.

Pentraxin-3 (PTX3) is a multifunctional patternrecognition molecule released at the onset of inflammation as part of the innate immune system by activating the classical and lectin complement pathways through specific recognition of the $\mathrm{C} 1 \mathrm{q}$, mannose-binding lectin, ficolin-1 and ficolin-2 subunits [9-13]. A high PTX3 level is associated with disease severity and mortality in patients with myocardial infarction [14-16], ischemic stroke [17], cancer [18, 19], acute respiratory distress syndrome [20] and sepsis [21-23]. PTX3 is closely related to CRP as both are members of the pentraxin family of proteins, and PTX3 is central to the antimicrobial responses and in the clearance of cellular debris.

As PTX3 is produced locally by various cells, including monocytes, neutrophils and endothelial cells in response to tumor necrosis factor and bacterial products, it is reasonable to consider PTX3 as a marker of local inflammation detected by direct release to the blood stream [24]. In contrast, CRP is produced in the liver in response to locally induced interleukin-6 $[25,26]$, while the expression and synthesis of PCT in response to inflammatory stimuli seems to be more ubiquitous [27]. Despite the promising role of PTX3 in the risk stratification of various infections and inflammatory conditions, the prognostic relevance in patients with NSTI remains to be evaluated.

The aim of this study was to assess plasma PTX3 as a marker of disease severity and risk of death in patients with NSTI.

\section{Methods}

\section{Study design and setting}

This prospective, observational study was conducted during February 2013 to March 2015 at Copenhagen University Hospital (Rigshospitalet) as a substudy of the ongoing European INFECT project (ClinicalTrials.gov Identifier: NCT01790698). The protocol of this study is described in greater detail elsewhere [28] and registered at ClinicalTrials.gov (NCT02180906). In Denmark (population 5.6 million) the treatment of NSTI is centralized at a tertiary referral hospital, Rigshospitalet, University of Copenhagen.

\section{Study population \\ Patients with NSTI}

Patients were included if they had been: (1) diagnosed with NSTI based on surgical findings with necrosis engaging any layers of the soft tissue compartments; (2) aged $\geq 18$ years; and (3) had either been admitted to the ICU or undergone surgery for NSTI at Rigshospitalet. Patients were excluded if the NSTI diagnosis could not be confirmed during surgery. For the majority of patients, the first operation had been at a primary hospital before the transfer to our center.

\section{Control patients}

Control patients were eligible for inclusion if they were: (1) undergoing elective orthopedic surgery at Rigshospitalet; and (2) were aged $\geq 18$ years. Patients with ongoing infection or inflammatory conditions were excluded. We included 65 control patients, matched for age and sex during September 2014 to March 2015.

\section{Data collection \\ Clinical data}

We obtained data from electronic records on age, sex, body mass index, chronic disease (diabetes, liver cirrhosis, chronic kidney disease, cardiovascular disease, chronic obstructive pulmonary disease, peripheral vascular disease, immune deficiency, malignancy, rheumatoid disease), primary site of infection, microorganism, biochemistry, ICU scoring systems and treatment. Vital status and time of death, if relevant, were extracted from the hospital database linked to the Danish Civil Registration System. The criterion for amputation was based on the surgeon's clinical evaluation of the infected body part and performed as a final method to obtain infection control. No strict protocol for amputation was used. 


\section{Blood sampling and processing}

Blood was drawn from an arterial line into 9-mL vacuum tubes containing EDTA at four discrete time points: on admission (baseline) and the following three days between 8 a.m. and 12 a.m. For the control group, the blood samples were drawn by venous puncture at three discrete time points: preoperatively (baseline), 2-6 h postoperatively and the day after surgery between 8 a.m. and 12 a.m. The blood sample was immediately put on ice until plasma was separated from the whole blood by centrifugation (within 40 minutes) at $3500 \mathrm{rpm}(2400 \mathrm{G})$ for 10 minutes and was subsequently stored at $-80{ }^{\circ} \mathrm{C}$.

\section{Routine biochemistry and hematology}

Standard blood analyses including platelet count, creatinine, leucocyte count, PCT and CRP levels were performed at the Department of Clinical Biochemistry, Rigshospitalet, as part of routine analyses, whereas sodium, potassium, hemoglobin, lactate, $\mathrm{pH}$, base excess, $\mathrm{pO}_{2}$ and $\mathrm{pCO}_{2}$ were measured using an ABL 725 (Radiometer, Copenhagen, Denmark).

\section{Enzyme-linked immunosorbent assay}

Plasma PTX3 levels were determined using anti-PTX3 monoclonal antibodies in a sandwich enzyme-linked immunosorbent assay (ELISA) developed in the Laboratory of Molecular Medicine, Rigshospitalet, according to previously described procedures $[23,29]$. In short, microtiter plates (Nunc Immuno Plates, F384 Maxisorp) were coated with $2 \mu \mathrm{g} / \mathrm{mL}$ mouse monoclonal anti-PTX3 antibody (clone PTX-66) produced inhouse [23], diluted in phosphate-buffered saline $+0.05 \%$ Tween-20 (PBS-T), and incubated overnight. The plasma samples were diluted with sample buffer (1:20) in triplicates and incubated for $3 \mathrm{~h}$. The biotinylated anti-PTX3 detection antibody (clone PTX3-20) was diluted $(1 \mu \mathrm{g} / \mathrm{mL})$, applied to the wells and incubated overnight. Secondary streptavidin-horseradish peroxidase conjugate was applied for $2 \mathrm{~h}$. The plates were developed with OPD substrate and hydrogen peroxide. The optical density was measured at $490 \mathrm{~nm}$ with an ELISA reader. Inhouse-produced biologically active recombinant PTX3 was used as a calibrator. The sensitivity of the PTX3 assay in plasma has been estimated to be $1.5 \mathrm{ng} / \mathrm{mL}$ with an intra-assay variation of $5 \%$ and interassay variation of $10 \%$.

\section{Outcome measures}

Our primary analysis focused on the association between baseline PTX3 level and disease severity by comparing plasma PTX3 level in NSTI patients with and without septic shock upon admission to our center. This comparison was performed due to an expected higher mortality rate in patients with septic shock, thereby making it a clinically relevant stratification. Septic shock was defined according to the criteria of Bone et al. [30].

Secondary analyses compared PTX3 level during the following 3 days between nonshock patients versus patients with septic shock, amputation versus no amputation, and NSTI patients versus control patients. Additionally, analyses included investigation of differences in 180-day mortality and long-term mortality up to 2.5 years between NSTI patients with high versus low levels (dichotomization by median) of PTX3, PCT and CRP. Patients were followed from the date of admission to the first of the following: death or the end of the follow-up (August 2015).

\section{Statistical analysis}

Kolmogorov-Smirnov and Shapiro-Wilk normality tests were performed for all variables. Due to nonparametric distribution, continuous data are reported as median (interquartile range (IQR)). For categorical data we reported absolute numbers (proportions) with the use of $X^{2}$-test or Fisher's exact test for comparisons. Continuous data were compared at specific time points using Mann-Whitney $U$ test. Correlations were assessed using the Spearman's rank correlation test. The prognostic value of PTX3 for long-term mortality up to 2.5 years was investigated using the log-rank test. The prognostic value of PTX3, PCT and CRP for 180-day mortality was investigated using the univariate Cox analysis. For multivariate analysis, the Cox proportional hazards regression model was used with adjustment for age, sex, Simplified Acute Physiology Score II (SAPS II) and chronic disease (yes/no). We were unable to calculate SAPS II in five patients due to missing data. These patients were excluded from the multivariate analysis. Data from the Cox analyses are presented as relative hazards with $95 \%$ confidence intervals (CI). Area under the curve (AUC) and receiver operating characteristic (ROC) curves were reported for the inflammatory biomarkers for 180-day mortality. The optimal cutoff was identified as the value corresponding to the maximum sum of sensitivity and specificity.

$P$-values $<0.05$ were considered significant. Statistical analyses were performed using Statistical Package for the Social Sciences 22.0 software (SPSS Inc., Chicago, IL, USA) and GraphPad Prism 6.0 software (GraphPad Inc., La Jolla, CA, USA).

\section{Sample size}

On the basis of previous studies using the same analysis [23], the investigators expected a mean PTX3 level on admission of $120 \mathrm{ng} / \mathrm{mL}$ in the nonshock group and a mean PTX3 level of $210 \mathrm{ng} / \mathrm{mL}$ in the shock group. Assuming a standard deviation of $100 \mathrm{ng} / \mathrm{mL}$, 
detection of this difference with a statistical power of $90 \%$ at a $5 \%$ significance level would require inclusion of 52 patients. The groups were expected to be unequal in size (1:4); therefore we needed to include at least 82 patients.

\section{Ethics}

The study was approved by the regional ethics committee (H-2-2014-071) and the Danish Data Protection Agency (J. no. 30-1282) and registered at ClinicalTrials.gov (NCT02180906). Written informed consent was obtained from all patients or their legal substitute.

The manuscript was prepared according to the Strengthening the Reporting of Observational Studies in Epidemiology (STROBE) statement [31].

\section{Results}

Of 165 patients with suspected NSTI, 162 were included (Fig. 1). Subsequently, 27 patients were excluded because the NSTI diagnosis could not be verified during surgery. Thus, the study population consisted of 135 NSTI patients with a median age of 61 years (range, 52-69); $71 \%(\mathrm{n}=96$ (95\% CI, 63-78)) had septic shock, amputation was undertaken in $20 \%(\mathrm{n}=27(95 \% \mathrm{CI}, 14-28))$ and the 180-day mortality was $27 \%(\mathrm{n}=36(95 \% \mathrm{CI}$, 20-35)) (Tables 1 and 2).

\section{Association between pentraxin-3 and disease severity}

Baseline PTX3 level was significantly higher in patients with septic shock (67.3 (IQR, 28.8-213.5) versus 24.6 (IQR, 10.7-58.0) ng/mL, $p<0.0001$ ) (Fig. 2a). Moreover, baseline PTX3 level was significantly higher in patients who underwent amputation during the first 7 days in the ICU (118.6 (IQR, 42.4-219.6) versus 43.6 (IQR, $15.5-153.1) \mathrm{ng} / \mathrm{mL}, p=0.019$ ) (Fig. 2b) and significantly higher in patients who died within the first 180 days after admission (124.3 (IQR, 43.1-210.8) versus 40.0 (IQR, 14.6-134.9) ng/mL, $p=0.005$ ) (Fig. 2c).

In general, the PTX3 level decreased during admission to the ICU, but it increased over the first day for those with a fatal outcome whilst the PTX3 levels decreased in survivors (168.3 (IQR, 44.9-324.7) versus 29.0 (IQR, $14.2-110.4) \mathrm{ng} / \mathrm{mL}, p<0.0001)$. A similar pattern was observed in patients who underwent amputation versus no amputation (136.3 (IQR, 32.6-303.3) versus 32.0 (IQR, 14.7-123.2) ng/mL, $p=0.008$ ). Patients with a streptococcal infection had a higher baseline PTX3 level (93.9 (IQR, 22.1-283.5) versus 44.7 (IQR, 16.5-130.3) $\mathrm{ng} / \mathrm{mL}, p=0.035)$. No difference was observed between mono- and polymicrobial infection (44.0 (IQR, 16.9169.5 ) versus 65.2 (IQR, $19.8-174.3) \mathrm{ng} / \mathrm{mL}, p=0.346$ ). Lastly, the patients with NSTI had a significantly higher baseline PTX3 level compared with control patients

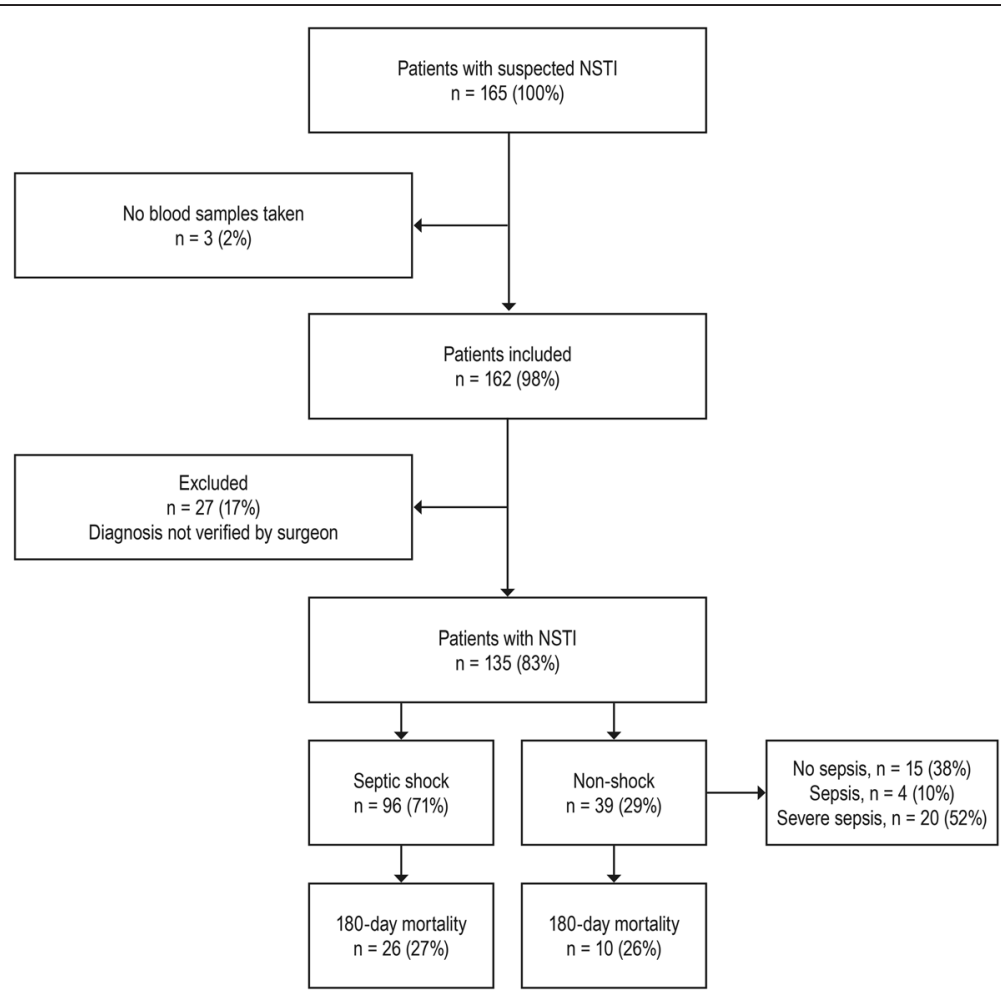

Fig. 1 Flow chart of patient inclusion. NSTI Necrotizing soft tissue infection 
Table 1 Baseline characteristics for the entire cohort of patients with necrotizing soft tissue infections and for the septic shock and nonshock (no sepsis, sepsis, severe sepsis) subgroups

\begin{tabular}{|c|c|c|c|c|}
\hline & $\begin{array}{l}\text { Entire cohort } \\
(n=135)\end{array}$ & $\begin{array}{l}\text { Nonshock } \\
(n=39)\end{array}$ & $\begin{array}{l}\text { Septic shock } \\
(n=96)\end{array}$ & $p$ \\
\hline Age, years & $61(52-69)$ & $58(48-70)$ & $62(54-69)$ & 0.426 \\
\hline Sex, male & $84(62)$ & $24(62)$ & $60(63)$ & 0.917 \\
\hline Body mass index, $\mathrm{kg} / \mathrm{m}^{2}$ & $26(23-31)$ & $24(22-31)$ & $27(25-32)$ & 0.017 \\
\hline \multicolumn{5}{|l|}{ Chronic disease } \\
\hline Chronic disease & $86(64)$ & $28(72)$ & $58(60)$ & 0.213 \\
\hline Diabetes & $30(22)$ & $10(26)$ & $20(21)$ & 0.543 \\
\hline Liver cirrhosis & $5(4)$ & $1(3)$ & $4(4)$ & 0.655 \\
\hline Chronic kidney disease & $12(9)$ & $6(15)$ & $6(6)$ & 0.104 \\
\hline Cardiovascular disease & $58(43)$ & $21(54)$ & $37(39)$ & 0.103 \\
\hline Chronic obstructive pulmonary disease & $14(10)$ & $3(8)$ & $11(12)$ & 0.757 \\
\hline Peripheral vascular disease & $20(15)$ & $8(21)$ & $12(13)$ & 0.235 \\
\hline Immune deficiency/AIDS & $3(2)$ & $2(5)$ & $1(1)$ & 0.200 \\
\hline Malignancy & $15(11)$ & $3(8)$ & $12(13)$ & 0.553 \\
\hline Rheumatoid disease & $10(7)$ & $2(5)$ & $8(8)$ & 0.723 \\
\hline Active smoker & $40(30)$ & $9(23)$ & $31(32)$ & 0.366 \\
\hline High alcohol consumption ${ }^{a}$ & $19(14)$ & $3(8)$ & $16(17)$ & 0.191 \\
\hline Steroid treatment & $16(12)$ & $4(10)$ & $12(13)$ & 0.277 \\
\hline Immunosuppressing drugs & $12(9)$ & $3(8)$ & $9(9)$ & 0.281 \\
\hline \multicolumn{5}{|l|}{ Primary site of infection } \\
\hline Head/neck & $21(15)$ & $6(16)$ & $15(16)$ & 0.972 \\
\hline Upper extremity & $15(11)$ & $3(8)$ & $12(13)$ & 0.553 \\
\hline Lower extremity & $47(35)$ & $13(33)$ & $34(35)$ & 0.818 \\
\hline Chest & $5(4)$ & $2(5)$ & $3(3)$ & 0.626 \\
\hline Abdomen & $11(8)$ & $2(5)$ & $9(9)$ & 0.510 \\
\hline Genital/perineum & $36(27)$ & $13(33)$ & $23(24)$ & 0.264 \\
\hline \multicolumn{5}{|l|}{ Microorganism } \\
\hline Positive cultures & $100(74)$ & $25(64)$ & $75(78)$ & 0.128 \\
\hline Polymicrobial & $54(40)$ & $13(33)$ & $41(43)$ & 0.339 \\
\hline Beta-hemolytic streptococcus & $46(34)$ & $9(23)$ & $37(39)$ & 0.120 \\
\hline Staphylococcus aureus & $14(10)$ & $2(5)$ & $12(13)$ & 0.350 \\
\hline Anaerobes & $23(17)$ & $9(23)$ & $14(15)$ & 0.312 \\
\hline Gram negative rods & $25(19)$ & $6(15)$ & $19(20)$ & 0.632 \\
\hline Other & $15(11)$ & $5(13)$ & $10(10)$ & 0.764 \\
\hline
\end{tabular}

Values denote median (interquartile range) or number (\%). Differences between the shock and nonshock group were tested using Mann-Whitney $U$ or $\chi^{2}$-test/Fisher's exact test

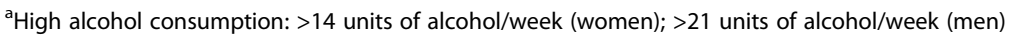

without infection (52.4 (IQR, 17.7-172.2) versus 2.9 (IQR, 2.0-4.5) ng/mL, $p<0.0001$ ) (Fig. 2d).

\section{Procalcitonin and C-reactive protein}

Baseline PCT level was significantly higher in patients with septic shock (13.6 (IQR, 2.9-37.8) versus 1.5 (IQR, $0.3-7.2) \mu \mathrm{g} / \mathrm{L}, p<0.0001)$, whilst no significant difference in baseline CRP level was observed (222 (IQR, 152-302) versus 201 (IQR, 134-275) $\mathrm{mg} / \mathrm{mL}, p=0.295$ ) (Table 2). There were no significant differences in baseline PCT or CRP levels according to amputation (25.2 (IQR, 1.9-78.5) versus 7.0 (IQR, 1.4-22.7) $\mu \mathrm{g} / \mathrm{L}, p=0.060$ and 202 (IQR, 90-244) versus 225 (IQR, 143-307) $\mathrm{mg} / \mathrm{L}, p=0.123)$, respectively.

PTX3 correlated with PCT (Rho $=0.64(95 \% \mathrm{CI}$, $0.52-0.73), p<0.0001)$ and SAPS II (Rho $=0.45(95 \% \mathrm{CI}$, 
Table 2 Laboratory values, clinical scoring systems and outcomes for the entire cohort of patients with necrotizing soft tissue infections and for the septic shock and nonshock (no sepsis, sepsis, severe sepsis) subgroups

\begin{tabular}{|c|c|c|c|c|}
\hline & $\begin{array}{l}\text { Entire cohort } \\
(n=135)\end{array}$ & $\begin{array}{l}\text { Nonshock } \\
(n=39)\end{array}$ & $\begin{array}{l}\text { Septic shock } \\
(n=96)\end{array}$ & $p$ \\
\hline \multicolumn{5}{|l|}{ Biomarker level upon admission (baseline) } \\
\hline Pentraxin-3, ng/mL & $52.4(17.7-172.2)$ & $24.6(10.7-58.0)$ & $67.3(28.8-213.5)$ & $<0.0001$ \\
\hline Procalcitonin, $\mu \mathrm{g} / \mathrm{L}$ & $7.7(1.4-28.8)$ & $1.5(0.3-7.2)$ & $13.6(2.9-37.8)$ & $<0.0001$ \\
\hline C-reactive protein, mg/L & $222(141-298)$ & $201(134-275)$ & $222(152-302)$ & 0.295 \\
\hline \multicolumn{5}{|l|}{ Biochemistry } \\
\hline Leukocyte count, $10^{9} / \mathrm{L}$, highest value & $16.9(10.4-23.9)$ & $15.5(9.7-22.7)$ & $17.6(12.2-24.5)$ & 0.197 \\
\hline $\mathrm{Na}^{+}, \mathrm{mmol} / \mathrm{L}$, lowest value & $136(132-138)$ & $136(134-139)$ & $135(131-138)$ & 0.198 \\
\hline $\mathrm{K}^{+}, \mathrm{mmol} / \mathrm{L}$, highest value & $4.3(4.0-4.9)$ & $4.1(3.8-4.3)$ & $4.5(4.1-5.2)$ & $<0.0001$ \\
\hline Glucose, mmol/L, highest value & $8.3(7.1-11.5)$ & $7.5(5.8-9.9)$ & $8.6(7.3-12.4)$ & 0.011 \\
\hline Creatinine, $\mu \mathrm{mol} / \mathrm{L}$, highest value & $119(77-205)$ & $82(58-127)$ & $142(82-229)$ & 0.002 \\
\hline Hemoglobin, mmol/L, lowest value & $5.7(4.9-6.5)$ & $5.7(4.9-6.7)$ & $5.7(4.8 .9-6.3)$ & 0.429 \\
\hline $\mathrm{pH}$, lowest value & $7.30(7.20-7.37)$ & $7.35(7.29-7.40)$ & $7.28(7.18-7.34)$ & 0.006 \\
\hline $\mathrm{pO}_{2}, \mathrm{kPa}$, from lowest $\mathrm{PaO}_{2} / \mathrm{FiO}_{2}$ ratio & $13.7(10.9-19.7)$ & $14.4(11,5-22.3)$ & $12.8(10.8-18.1)$ & 0.137 \\
\hline Base excess, $\mathrm{mmol} / \mathrm{L}$, lowest value & $-5.5(-9.4$ to -1.8$)$ & $-2.2(-5.7$ to -2.2$)$ & $-6.7(-10.9$ to -2.5$)$ & 0.001 \\
\hline Lactate, $\mathrm{mmol} / \mathrm{L}$, highest value & $1.9(1.1-4.1)$ & $1.0(0.7-1.6)$ & $2.5(1.5-5.0)$ & $<0.0001$ \\
\hline \multicolumn{5}{|l|}{ ICU scoring systems and treatment } \\
\hline SAPS $\|^{a}$ & $45(35-52)$ & $35(29-48)$ & $46(39-56)$ & 0.001 \\
\hline SOFA (day 1$)^{\mathrm{b}}$ & $7(4-10)$ & $3(2-5)$ & $8(7-10)$ & $<0.0001$ \\
\hline LRINEC $^{C}$ & $8(6-9)$ & $8(5-9)$ & $8(6-10)$ & 0.103 \\
\hline ICU admission ${ }^{d}$ & $123(91)$ & $28(72)$ & $95(99)$ & $<0.0001$ \\
\hline Ventilator treatment & $122(90)$ & $27(70)$ & $95(99)$ & $<0.0001$ \\
\hline Renal replacement therapye & $34(25)$ & $5(13)$ & $29(30)$ & 0.035 \\
\hline Amputation of limb or penis ${ }^{\mathrm{e}}$ & $27(20)$ & $5(13)$ & $22(23)$ & 0.184 \\
\hline \multicolumn{5}{|l|}{ Mortality } \\
\hline 28-day (\%, 95 \% Cl) & $22(16,11-24)$ & $8(21,11-36)$ & $14(15,9-23)$ & 0.398 \\
\hline 90-day (\%, 95 \% Cl) & $31(23,17-31)$ & $9(23,12-39)$ & $22(23,16-32)$ & 0.984 \\
\hline 180-day (\%, 95 \% Cl) & $36(27,20-35)$ & $10(26,14-41)$ & $26(27,19-37)$ & 0.864 \\
\hline Long-term up to 2.5 years $^{\mathrm{f}}(\%, 95 \% \mathrm{Cl})$ & $44(33,25-41)$ & $12(31,18-47)$ & $32(33,25-43)$ & 0.773 \\
\hline
\end{tabular}

Values denote median (interquartile range) or number (\%). Differences between the shock and non-shock group were tested using Mann-Whitney $U$ or $X^{2}$-test/ Fisher's exact test

${ }^{a}$ Number of patients with missing values: $\mathrm{n}=5$ ( $\mathrm{n}=3$ for nonshock; $\mathrm{n}=2$ for shock)

${ }^{b}$ Number of patients with missing values: $n=6$ ( $n=3$ for nonshock; $n=3$ for shock)

'Number of patients with missing values: $n=15$ ( $n=9$ for nonshock; $n=6$ for shock)

${ }^{\mathrm{d}}$ Three patients died before admission to the ICU ( $\mathrm{n}=2$ for nonshock; $\mathrm{n}=1$ for shock)

eWithin the first 7 days in the ICU

${ }^{\mathrm{f}} \mathrm{A}$ follow-up up to 2.5 years

CI Confidence interval, ICU Intensive care unit, LRINEC Laboratory risk indicator for necrotizing fasciitis, SAPS Simplified Acute Physiology Score, SOFA Sequential

Organ Failure Assessment

0.30-0.58), $p<0.0001$ ) but not with CRP (Rho $=0.15$ (95\% CI, -0.03-0.32), $p=0.095$ ). Moreover, baseline PTX3 correlated with the Sequential Organ Failure Assessment (SOFA) score (Rho $=0.48(95 \% \mathrm{CI}, 0.34-0.60)$, $\mathrm{p}<0.0001)$ and baseline lactate level (Rho $=0.57(95 \%$ CI, 0.44-0.67), $p<0.0001)$. PTX3 also correlated with creatinine $(\mathrm{Rho}=0.46$ (95\% CI, 0.31-0.58), $p<0.0001)$ and patients receiving renal replacement therapy within the first 7 days in the ICU had a higher baseline PTX3 level
(141.2 (IQR, 55.0-276.4) versus 34.5 (IQR, 13.0-124.3) $\mathrm{ng} / \mathrm{mL}, p<0.0001)$.

\section{Univariate survival analysis}

During a median follow-up of 17 months (range 3-30 months), 44 patients died (32 with septic shock upon admission). Baseline PTX3 level above the median of $52.4 \mathrm{ng} / \mathrm{mL}$ was associated with lower survival rate $(p=0.009)$ (Fig. 3). Univariate survival analysis revealed 


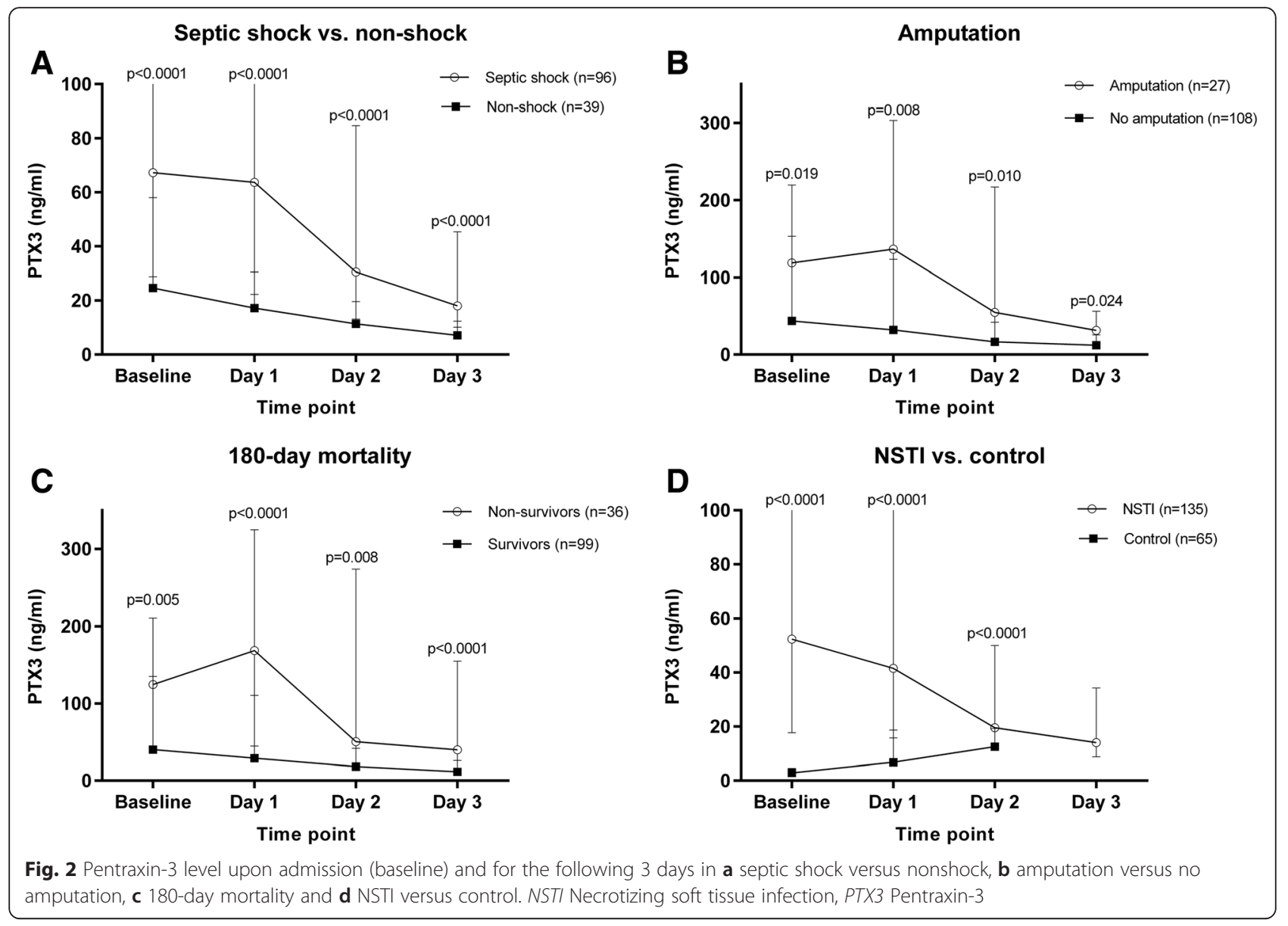

that age, SAPS II, PTX3, PCT and CRP were significantly associated with 180-day mortality (Table 3).

\section{Multivariate survival analysis}

When adjusted for variables specified in our protocol [28], the association between high baseline PTX3 level and 180-day mortality was not significant (hazard ratio

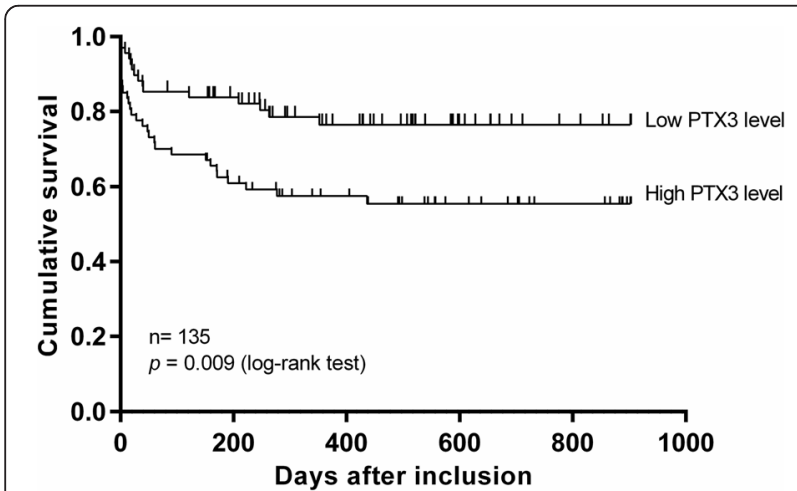

Fig. 3 Kaplan-Meier curves of long-term mortality up to 2.5 years in patients with necrotizing soft tissue infections stratified by median plasma PTX3 level (>52.4 ng/mL). PTX3 Pentraxin-3
(HR) 1.05 (95\% CI, 0.47-2.35), $p=0.902$ ) (Table 4). The same lack of association was observed for PCT (HR 0.86 (95\% CI, 0.38-1.95), $p=0.713$ ) and CRP (HR 0.71 (95\% CI, 0.34-1.51), $p=0.376$ ).

\section{Diagnostic accuracy of the inflammatory biomarkers to predict 180-day mortality}

We found low levels of sensitivity and specificity for PTX3, PCT and CRP in the analysis of 180-day mortality when the medians were used to define high versus low baseline levels in plasma (Table 4).

The AUC for the ROC was low for PTX3 levels (AUC $=0.66, p=0.005)$, as was the case for PCT levels (AUC $=0.65, p=0.007$ ) and CRP levels (AUC $=0.32$, $p=0.001$ ) (Fig. 4). The AUC improved when the inflammatory markers were combined (AUC $=0.72, p<0.0001$ ). The optimal cutoff for PTX3 was $69.8 \mathrm{ng} / \mathrm{mL}$, identified as the value corresponding to the maximum sum of sensitivity (0.67) and specificity (0.68). When the multivariate analysis was performed with the optimal cutoff instead of the median, the risk of 180-day mortality in patients with a high baseline PTX3 level increased but was still not significant (HR 1.34 (95 \% CI, 0.60-3.00), $p=0.480$ ) (Table 4). 
Table 3 Cox univariate analysis for 180-day mortality

\begin{tabular}{lllll}
\hline Variable & $\mathrm{n}$ & \multicolumn{3}{l}{ 180-day mortality } \\
\cline { 3 - 5 } & & $\mathrm{HR}$ & $95 \% \mathrm{Cl}$ & $\mathrm{p}$ \\
\hline Age, years & 135 & 1.04 & $1.01-1.07$ & 0.005 \\
SAPS II, point & 130 & 1.06 & $1.05-1.08$ & $<0.0001$ \\
Sex & & & & \\
$\quad$ Female & 51 & ref. & & 0.331 \\
$\quad$ Male & 84 & 1.42 & $0.70-2.89$ & \\
Chronic disease & & & & \\
$\quad$ No & 49 & ref. & & \\
$\quad$ Yes & 86 & 1.81 & $0.85-3.84$ & \\
Pentraxin-3 & & & & 0.008 \\
Low $\leq 52.4 \mathrm{ng} / \mathrm{mL}$ & & ref. & & \\
High $>52.4 \mathrm{ng} / \mathrm{mL}$ & & 2.60 & $1.28-5.29$ & \\
Procalcitonin & & & & 0.024 \\
Low $\leq 7.73 \mu \mathrm{g} / \mathrm{L}$ & & ref. & & \\
High $>7.73 \mu \mathrm{g} / \mathrm{L}$ & & 2.22 & $1.11-4.44$ & \\
C-reactive protein & & & & \\
Low $\leq 222 \mathrm{mg} / \mathrm{L}$ & & ref. & & \\
High $>222 \mathrm{mg} / \mathrm{L}$ & & 0.44 & $0.22-0.89$ & \\
\hline
\end{tabular}

Markers are divided by high versus low concentrations according to median values

CI Confidence interval, HR Hazard ratio, ref. Referent, SAPS I/ Simplified Acute Physiology Score II

\section{Discussion}

We found that a high PTX3 level in patients with NSTI at time of admission was associated with septic shock, renal replacement therapy, amputation and risk of death. High PCT and CRP levels were not associated with amputation. Moreover, baseline PTX3 level correlated with SAPS II, SOFA score, lactate and creatinine. None of the inflammatory biomarkers was significantly associated with 180-day mortality in the multivariate analysis and there was a low sensitivity, specificity and AUC. However, the AUC improved when the markers were combined.

PTX3 levels have been shown to be $1-2 \mathrm{ng} / \mathrm{mL}$ in healthy individuals $[32,33]$. In a recent study using the same assay, healthy individuals had a median PTX3 level of $3.5 \mathrm{ng} / \mathrm{mL}$ (range, $0.0-8.3 \mathrm{ng} / \mathrm{mL}$ ) [29] compared with $2.9 \mathrm{ng} / \mathrm{mL}$ (range, $1.7-28.5 \mathrm{ng} / \mathrm{mL}$ ) in the control patients in this study. The wider range might be explained by our control patients being matched by age and sex, thereby giving older controls with comorbidities that contribute to increased PTX3 levels. Nevertheless, we found significantly higher levels in the patients with NSTI underlining PTX3 as a marker of bacterial infection. However, PTX3 is not a specific marker for bacterial infections, which is why we adjusted our analysis for comorbidities, such as cardiovascular disease and malignancy, where high PTX3 levels have been shown to be correlated with disease severity and mortality [14, 15, 18, 34]. When adjusted for age, sex, chronic disease and SAPS II, the association between high PTX3 level upon admission and 180-day mortality was not significant, indicating that PTX3 is not an independent predictor of 180-day mortality. The same was observed for PCT and CRP. In line with this, we did not find a difference in mortality between septic shock versus nonshock patients (Table 2), which could otherwise be expected. This probably reflects that we did not include enough patients to demonstrate a difference in an outcome with low incidence.

It should be noted that the ROC-AUC for 180-day mortality was low but comparable to a previous study investigating PTX3, PCT and CRP in emergency room patients with suspected infection [35]. It confirms that these inflammatory biomarkers should be incorporated as part of an overall assessment of patients with NSTI

Table 4 Multivariate analysis by Cox proportional hazards regression model and diagnostic accuracy of 180-day mortality

\begin{tabular}{|c|c|c|c|c|c|c|c|c|c|c|}
\hline \multirow[t]{2}{*}{ Markers } & \multicolumn{10}{|c|}{ 180-day mortality } \\
\hline & $\mathrm{HR}^{\mathrm{a}}$ & $95 \% \mathrm{Cl}$ & $p$ & Sensitivity & $95 \% \mathrm{Cl}$ & Specificity & $95 \% \mathrm{Cl}$ & ROC-AUC & $95 \% \mathrm{Cl}$ & $p$ \\
\hline PTX3 & 1.05 & $0.47-2.35$ & 0.902 & 0.69 & $0.53-0.82$ & 0.56 & $0.50-0.60$ & 0.66 & $0.56-0.76$ & 0.005 \\
\hline PTX3 ${ }^{b}$ & 1.34 & $0.60-3.00$ & 0.480 & 0.67 & $0.51-0.80$ & 0.68 & $0.62-0.72$ & . & . & . \\
\hline PCT & 0.86 & $0.38-1.95$ & 0.713 & 0.66 & $0.50-0.79$ & 0.55 & $0.49-0.60$ & 0.65 & $0.55-0.76$ & 0.007 \\
\hline CRP & 0.71 & $0.34-1.51$ & 0.376 & 0.34 & $0.21-0.50$ & 0.41 & $0.36-0.47$ & 0.32 & $0.21-0.43$ & 0.001 \\
\hline $\mathrm{PTX} 3+\mathrm{PCT}$ & . & . & . & . & . & . & . & 0.66 & $0.56-0.76$ & 0.005 \\
\hline PTX3 + CRP & . & . & . & . & . & . & . & 0.72 & $0.61-0.82$ & $<0.0001$ \\
\hline$P C T+C R P$ & . & . & . & . & . & . & . & 0.71 & $0.60-0.82$ & $<0.0001$ \\
\hline $\mathrm{PTX} 3+\mathrm{PCT}+\mathrm{CRP}$ & . & . & . & . & . & . & . & 0.72 & $0.62-0.83$ & $<0.0001$ \\
\hline
\end{tabular}

Hazard ratio, sensitivity and specificity are calculated for high (above median) versus low (below median) baseline levels of the inflammatory biomarkers. Five patients are not included in the analysis due to missing data regarding Simplified Acute Physiology Score II

${ }^{a}$ Adjusted for age, sex, Simplified Acute Physiology Score II and chronic disease (yes/no)

${ }^{b}$ PTX3 dichotomized by the optimal cutoff $(69.8 \mathrm{ng} / \mathrm{ml})$ found by the ROC curve (highest sum of sensitivity and specificity) CRP C-reactive protein, HR Hazard ratio, PCT Procalcitonin, PTX3 Pentraxin-3, ROC-AUC Receiver operating characteristic-area under the curve, CI Confidence interval Dots: Values cannot be given 


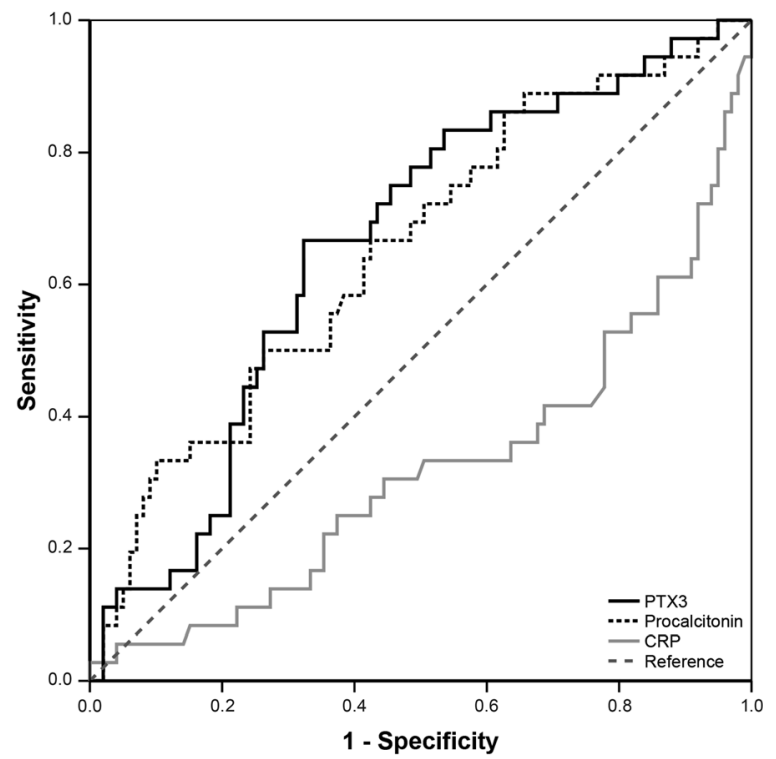

Fig. 4 Receiver operating characteristic curve of 180-day mortality in patients with necrotizing soft tissue infections for the inflammatory biomarkers. CRP C-reactive protein, PTX3 Pentraxin-3

rather than instead of clinical assessment. This is in line with previous studies investigating patients with sepsis or septic shock that found PCT and CRP to have limited abilities to predict outcome [36-38]. However, we found that the AUC improved when the inflammatory markers were combined. It may indicate that PTX3 in combination with other inflammatory markers can be used to discern severe NSTI from milder courses in order to refine the risk stratification. In particular, PTX3 level was higher in patients needing amputation during the first 7 days in the ICU, whereas PCT and CRP were not. Therefore, PTX3 might be used to identify the high-risk patients who require aggressive surgery, while directing a conservative approach to low-risk patients. The correlation between PTX3 and SAPS II may also suggest that PTX3 can be used as an easy assessment of disease severity until SAPS II can be calculated or in cases where SAPS II cannot be calculated due to missing values. An explanation for the association between high PTX3 level and increased disease severity and mortality may be found in the biological action of PTX3 as it is released in response to proinflammatory stimuli from interleukin-1 and tumor necrosis factor, thus potentially reflecting higher bacterial loads. PTX3 also acts as a modulator of the complement system, but a pathophysiological role related to tissue damage by amplifying the complement pathways remains to be elucidated.

To our knowledge, this is one of the largest prospective observational study cohorts of patients with NSTI and the first study to investigate the prognostic value of PTX3 in patients with NSTI. It is a strength that we managed to include $98 \%$ of all patients transferred to our center where the treatment of NSTI has been centralized at a national level and that multiple measurements from each patients were obtained. Moreover, this study was based on standardized sampling procedures ensured by using only a few individuals as part of a 24-h on-call team with nine members. Lastly, the external validity of the study results is high due to few inclusion and exclusion criteria, thus increasing the chance of the study cohort representing the vast majority of patients with NSTI and making the results applicable to daily clinical settings.

Several limitations must be considered. Firstly, the study might be subject to potential bias as a consequence of the inability to control for unknown confounders. Patients with NSTI represent a complex study population as seen by the range and variance in age, microbiologic agents, site of infection and comorbidities, thus making it difficult to isolate factors that potentially affect the immunological response. Importantly, these factors were not significantly different between patients with septic shock and the other patients. Secondly, we might have been able to minimize risk of observer and detection bias if the individuals who reviewed the medical records and did the statistical analyses had been blinded. However, the staff performing the laboratory analyses of PTX3, PCT and CRP were blinded to study purpose and patient outcome. Thirdly, almost one out of 10 patients did not have sepsis according to the international criteria by Bone et al. [30] (Fig. 1). This relatively large proportion might be explained by the fact that most patients had to be transferred to our center to be included. Some patients might have died before transfer or might have been too hemodynamically unstable to be transferred, thereby increasing the risk of selection bias. However, infections in critically ill patients can also be present without any clinical manifestation of the systemic inflammatory response syndrome [39], which is confirmed in this study cohort. It is crucial that clinicians know that patients with NSTI might not show the classical signs of sepsis. Lastly, it would have been interesting to have local PTX3 measurements from the focus of infection and compare this with the released amount in the blood stream. This could be incorporated in future study protocols as it, to our knowledge, has not been investigated before.

This study indicates that clinicians may consider PTX3 as a marker of infection on equal terms with PCT and that these markers are more reliable as prognostic markers of disease severity than is CRP in patients with NSTI. Additionally, these findings might be useful in creating homogenous patient groups for future clinical trials investigating NSTIs. It is important to note that multiple analyses were conducted and that PCT and CRP were secondary outcomes. This increases the risk 
of chance findings. Even though we found associations between PTX3 and clinical outcomes, the results should be interpreted with caution. The prognostic and predictive values need to be assessed in larger studies before PTX3 can be implemented in daily clinical practice. However, the results imply a potential role for PTX3 in severity and mortality prognostication in patients with NSTI.

\section{Conclusions}

We found that plasma PTX3 levels were associated with septic shock, renal replacement therapy, amputation and risk of death in patients with NSTI. However, PTX3 was not an independent predictor of 180-day mortality.

\section{Key messages}

- The largest to date prospective, observational study of patients with NSTI sampled over 25 months with up to 2.5-year follow-up.

- It is of topical interest that we now have a new inflammatory biomarker with a potential future role in severity and mortality prognostication in patients with NSTI.

- PTX3 level was higher in patients with NSTI needing amputation, whereas PCT and CRP were not. Therefore, PTX3 might be used to identify the highrisk patients who require aggressive surgery, while directing a conservative approach to low-risk patients.

- PTX3 is more reliable as a prognostic marker of disease severity than PCT and CRP in patients with NSTI.

- It is crucial that clinicians know that one out of 10 patients with NSTI might not show the classical signs of sepsis.

\begin{abstract}
Abbreviations
AUC: Area under the curve; Cl: Confidence interval; CRP: C-reactive protein; ELISA: Enzyme-linked immunosorbent assay; HZ: Hazard ratio; ICU: Intensive care unit; IQR: Interquartile range; NSTI: Necrotizing soft tissue infection; PCT: Procalcitonin; PTX3: Pentraxin-3; ROC: Receiver operating characteristic; SAPS II: Simplified Acute Physiology Score II; SOFA: Sequential Organ Failure Assessment.
\end{abstract}

\section{Competing interests}

MBM is subinvestigator on a randomized controlled trial that is partly funded by CSL Behring. The other authors declare that they have no competing interests.

\section{Authors' contributions \\ OH conceived the study. MBH, MBM, PG and LSR participated in study design and coordination. $\mathrm{MBH}, \mathrm{MBM}$ and $\mathrm{DB}$ participated in data acquisition. $\mathrm{MBH}$ and MBM maintained the database for analysis. MBH analyzed data. $\mathrm{MBH}, \mathrm{OH}, \mathrm{MBM}, \mathrm{LSR}, \mathrm{PG}$ and $\mathrm{DB}$ contributed to interpretation of data and were involved in drafting the manuscript and revising it critically. All authors read and approved the final version of the manuscript.}

\section{Acknowledgments}

We thank Jesper Andresen for help with the PTX3 analyses and Nina Falcon Bærnthsen, Morten Hedetoft, Anna Mygind Wahl, Marie Warrer Petersen, Peter Polzik and Isabel Guida Smidt-Nielsen for collecting blood samples. We also thank Peter Buhl Hjortrup, Matilde Jo Allingstrup and Rasmus Müller for help with patient inclusion and the research nurses Diana Isaksen and Jette Fredlund Degn for help with data acquisition.

\section{Funding}

The study was supported by the European Union FP7/2007-2013 (grant number 305340), Rigshospitalet Research Foundation (grant number E22514-02), Aase and Ejnar Danielsen Foundation (grant number 10-001274), Hans and Nora Buchard Foundation (grant number 7334), Director Jacob Madsen and Olga Madsen Foundation (grant number 5323), Christian Larsen and judge Ellen Larsen Foundation. Institutional departmental funds included Svend Andersen Research Foundation, Rigshospitalets Research Foundation, the Tryg Foundation and the Novo Nordisk Research Foundation.

\section{Author details}

'Department of Anesthesia, Center of Head and Orthopedics, Rigshospitalet, University of Copenhagen, Blegdamsvej 9, Copenhagen DK-2100, Denmark. ${ }^{2}$ Hyperbaric Unit, Department of Anesthesia, Center of Head and Orthopedics, Rigshospitalet, University of Copenhagen, Blegdamsvej 9, Copenhagen DK-2100, Denmark. 'Laboratory of Molecular Medicine, Department of Clinical Immunology, Rigshospitalet, University of Copenhagen, Blegdamsvej 9, Copenhagen DK-2100, Denmark. ${ }^{4}$ Department of Intensive Care, Rigshospitalet, University of Copenhagen, Blegdamsvej 9, Copenhagen DK-2100, Denmark.

Received: 23 November 2015 Accepted: 31 January 2016

Published online: 15 February 2016

\section{References}

1. Golger A, Ching S, Goldsmith CH, Pennie RA, Bain JR. Mortality in patients with necrotizing fasciitis. Plast Reconstr Surg. 2007;119:1803-7.

2. McHenry CR, Piotrowski JJ, Petrinic D, Malangoni MA. Determinants of mortality for necrotizing soft-tissue infections. Ann Surg. 1995:221:558-63.

3. Elliott DC, Kufera JA, Myers RA. Necrotizing soft tissue infections. Risk factors for mortality and strategies for management. Ann Surg. 1996;224:672-83.

4. Bilton BD, Zibari GB, McMillan RW, Aultman DF, Dunn G, McDonald JC. Aggressive surgical management of necrotizing fasciitis serves to decrease mortality: a retrospective study. Am Surg. 1998;64:397-400.

5. Wong C-H, Chang H-C, Pasupathy S, Khin L-W, Tan J-L, Low C-O. Necrotizing fasciitis: clinical presentation, microbiology, and determinants of mortality. J Bone Joint Surg Am. 2003;85-A:1454-60.

6. Yaghoubian A, de Virgilio C, Dauphine C, Lewis RJ, Lin M. Use of admission serum lactate and sodium levels to predict mortality in necrotizing softtissue infections. Arch Surg. 2007;142:840-6.

7. Friederichs J, Hutter M, Hierholzer C, Novotny A, Friess H, Bühren V, et al. Procalcitonin ratio as a predictor of successful surgical treatment of severe necrotizing soft tissue infections. Am J Surg. 2013;206:368-73.

8. Moore SA, Levy BH, Prematilake C, Dissanaike S. The prediction predicament: rethinking necrotizing soft tissue infections mortality. Surg Infect (Larchmt). 2015. doi:10.1089/sur.2015.002.

9. Ma YJ, Doni A, Hummelshøj T, Honoré C, Bastone A, Mantovani A, et al. Synergy between ficolin-2 and pentraxin 3 boosts innate immune recognition and complement deposition. J Biol Chem. 2009;284:28263-75.

10. Ma YJ, Doni A, Skjoedt M-O, Honoré C, Arendrup M, Mantovani A, et al. Heterocomplexes of mannose-binding lectin and the pentraxins PTX3 or serum amyloid $\mathrm{P}$ component trigger cross-activation of the complement system. J Biol Chem. 2011;286:3405-17.

11. Doni A, Garlanda C, Bottazzi B, Meri S, Garred P, Mantovani A. Interactions of the humoral pattern recognition molecule PTX3 with the complement system. Immunobiology. 2012;217:1122-8.

12. Ma YJ, Doni A, Romani L, Jürgensen $H J$, Behrendt N, Mantovani A, et al. Ficolin-1-PTX3 complex formation promotes clearance of altered self-cells and modulates IL-8 production. J Immunol. 2013;191:1324-33.

13. Vilahur G, Badimon L. Biological actions of pentraxins. Vascul Pharmacol. 2015;73:38-44.

14. Peri G, Introna M, Corradi D, lacuitti G, Signorini S, Avanzini F, et al. PTX3, a prototypical long pentraxin, is an early indicator of acute myocardial infarction in humans. Circulation. 2000;102:636-41.

15. Latini R, Maggioni AP, Peri G, Gonzini L, Lucci D, Mocarelli P, et al. Prognostic significance of the long pentraxin PTX3 in acute myocardial infarction. Circulation. 2004;110:2349-54. 
16. Kume N, Mitsuoka H, Hayashida K, Tanaka M. Pentraxin 3 as a biomarker for acute coronary syndrome: comparison with biomarkers for cardiac damage. J Cardiol. 2011;58:38-45.

17. Ryu W-S, Kim CK, Kim BJ, Kim C, Lee S-H, Yoon B-W. Pentraxin 3: a novel and independent prognostic marker in ischemic stroke. Atherosclerosis. 2012;220:581-6.

18. Diamandis EP, Goodglick L, Planque C, Thornquist MD. Pentraxin-3 is a novel biomarker of lung carcinoma. Clin Cancer Res. 2011;17:2395-9.

19. Choi B, Lee E-J, Song D-H, Yoon S-C, Chung Y-H, Jang Y, et al. Elevated pentraxin 3 in bone metastatic breast cancer is correlated with osteolytic function. Oncotarget. 2014;5:481-92.

20. Mauri T, Coppadoro A, Bellani G, Bombino M, Patroniti N, Peri G, et al. Pentraxin 3 in acute respiratory distress syndrome: an early marker of severity. Crit Care Med. 2008;36:2302-8.

21. Muller B, Peri G, Doni A, Torri V, Landmann R, Bottazzi B, et al. Circulating levels of the long pentraxin PTX3 correlate with severity of infection in critically ill patients. Crit Care Med. 2001;29:1404-7.

22. Mauri T, Bellani G, Patroniti N, Coppadoro A, Peri G, Cuccovillo I, et al. Persisting high levels of plasma pentraxin 3 over the first days after severe sepsis and septic shock onset are associated with mortality. Intensive Care Med. 2010;36:621-9.

23. Bastrup-Birk S, Skjoedt M-O, Munthe-Fog L, Strom JJ, Ma YJ, Garred P. Pentraxin-3 serum levels are associated with disease severity and mortality in patients with systemic inflammatory response syndrome. PLoS One. 2013;8:e73119

24. Jaillon S, Bonavita E, Gentile S, Rubino M, Laface I, Garlanda C, et al. The long pentraxin PTX3 as a key component of humoral innate immunity and a candidate diagnostic for inflammatory diseases. Int Arch Allergy Immunol. 2014;165:165-78.

25. Pepys MB, Baltz ML. Acute phase proteins with special reference to Creactive protein and related proteins (pentaxins) and serum amyloid $A$ protein. Adv Immunol. 1983;34:141-212.

26. Steel DM, Whitehead AS. The major acute phase reactants: C-reactive protein, serum amyloid $\mathrm{P}$ component and serum amyloid $\mathrm{A}$ protein. Immunol Today. 1994;15:81-8.

27. Müller B, White JC, Nylén ES, Snider RH, Becker KL, Habener JF. Ubiquitous expression of the calcitonin-i gene in multiple tissues in response to sepsis. J Clin Endocrinol Metab. 2001;86:396-404.

28. Hansen MB, Simonsen U, Garred P, Hyldegaard O. Biomarkers of necrotising soft tissue infections: aspects of the innate immune response and effects of hyperbaric oxygenation - the protocol of the prospective cohort BIONEC study. BMJ Open. 2015;5:e006995.

29. Bastrup-Birk S, Munthe-Fog L, Skjoedt M-O, Ma YJ, Nielsen H, Køber L, et al. Pentraxin-3 level at admission is a strong predictor of short-term mortality in a community-based hospital setting. J Intern Med. 2015;277:562-72.

30. Bone RC, Balk RA, Cerra FB, Dellinger RP, Fein AM, Knaus WA, et al. Definitions for sepsis and organ failure and guidelines for the use of innovative therapies in sepsis. The ACCP/SCCM Consensus Conference Committee. American College of Chest Physicians/Society of Critical Care Medicine. Chest. 1992;101:1644-55.

31. von Elm E, Altman DG, Egger M, Pocock SJ, Gøtzsche PC, Vandenbroucke $J$, et al. The Strengthening the Reporting of Observational Studies in Epidemiology (STROBE) statement: guidelines for reporting observational studies. Lancet. 2007;370:1453-7.

32. Yamasaki K, Kurimura M, Kasai T, Sagara M, Kodama T, Inoue K Determination of physiological plasma pentraxin 3 (PTX3) levels in healthy populations. Clin Chem Lab Med. 2009;47:471-7.

33. de Kruif MD, Limper M, Sierhuis K, Wagenaar JFP, Spek CA, Garlanda C, et al. PTX3 predicts severe disease in febrile patients at the emergency department. J Infect. 2010;60:122-7.

34. Jenny NS, Arnold AM, Kuller LH, Tracy RP, Psaty BM. Associations of pentraxin 3 with cardiovascular disease and all-cause death: the Cardiovascular Health Study. Arterioscler Thromb Vasc Biol. 2009;29:594-9.

35. Uusitalo-Seppälä R, Huttunen R, Aittoniemi J, Koskinen P, Leino A, Vahlberg T, et al. Pentraxin 3 (PTX3) is associated with severe sepsis and fatal disease in emergency room patients with suspected infection: a prospective cohort study. PLoS One. 2013;8:e53661.

36. Meisner M, Tschaikowsky K, Palmaers T, Schmidt J. Comparison of procalcitonin (PCT) and C-reactive protein (CRP) plasma concentrations at different SOFA scores during the course of sepsis and MODS. Crit Care. 1999:3:45-50,
37. Claeys R, Vinken S, Spapen H, ver Elst K, Decochez K, Huyghens L, et al. Plasma procalcitonin and C-reactive protein in acute septic shock: clinical and biological correlates. Crit Care Med. 2002;30:757-62.

38. Pierrakos C, Vincent J-L. Sepsis biomarkers: a review. Crit Care. 2010;14:R15

39. Alberti C, Brun-Buisson C, Goodman SV, Guidici D, Granton J, Moreno R, et al Influence of systemic inflammatory response syndrome and sepsis on outcome of critically ill infected patients. Am J Respir Crit Care Med. 2003;168:77-84.

\section{Submit your next manuscript to BioMed Central and we will help you at every step:}

- We accept pre-submission inquiries

- Our selector tool helps you to find the most relevant journal

- We provide round the clock customer support

- Convenient online submission

- Thorough peer review

- Inclusion in PubMed and all major indexing services

- Maximum visibility for your research

Submit your manuscript at www.biomedcentral.com/submit
) Biomed Central 